\title{
Qualitative and quantitative photogrammetric techniques for multi-temporal landslide analysis
}

\author{
Antonio Zanutta $\left({ }^{1}\right)$, Paolo Baldi $\left({ }^{2}\right)$, Gabriele Bitelli $\left({ }^{1}\right)$, Mauro Cardinali $\left({ }^{3}\right)$ and Alberto Carrara $\left({ }^{4}\right)$ \\ (') Dipartimento di Ingegneria delle Strutture, dei Trasporti, delle Acque, \\ del Rilevamento, del Territorio (DISTART), Università degli Studi di Bologna, Italy \\ ${ }^{2}{ }^{2}$ Dipartimento di Fisica, Università di Studi di Bologna, Italy \\ $\left(^{3}\right)$ Istituto di Elettronica e di Ingegneria dell'Informazione \\ e delle Telecomunicazioni (IEIIT), CNR, Bologna, Italy \\ $\left({ }^{4}\right)$ Istituto di Ricerca per la Protezione Idrogeologica (IRPI), CNR, Perugia, Italy
}

\begin{abstract}
The results of two survey methods, geological photointerpretation and historical photogrammetry, are compared in order to evaluate the temporal evolution of a unstable slope located in the Tuscan-Emilian Apennines (Italy). Historical aerial photos of the area, derived from photogrammetric surveys conducted in 1954 (scale 1:60000), in 1971 (scale 1:20000), and in 1976 (scale 1:17000) were available. A photogrammetric flight was further conducted in 2000, at a scale of 1:4400, with a traditional GPS ground survey support. First, the results of photographic analysis with the photointerpretation method are presented: the landslides are described from a geological point of view, showing its temporal evolution. To quantitatively assess the landslide movements, Digital Terrain Models were generated by means of an analytical plotter and a digital photogrammetric workstation, with semi-automatic and automatic procedures. To generate these products, it was necessary to solve problems related to a lack of data concerning the aerial cameras used for the historical flights (internal orientation) and the difficulty identifying control points on the photos in order to define the external orientation. An unconventional photogrammetric methodology, based on identification of homologous points in zones considered outside the landslide area, has been there developed and tested to insert the various surveys into a single reference system.
\end{abstract}

Key words photogrammetry - DTMs generation archival photographs - surface representation - landslide analysis

\section{Introduction}

The historical aerial photos are of fundamental importance not only for qualitative analysis of

Mailing address: Dr. Antonio Zanutta, Dipartimento di Ingegneria delle Strutture, dei Trasporti, delle Acque, del Rilevamento, del Territorio (DISTART), Università degli Studi di Bologna, Viale Risorgimento 2, 40136 Bologna, Italy; e-mail: antonio.zanutta@mail.ing.unibo.it. the territory (traditionally conducted by photointerpretation of stereoscopic models), but for a quantitative assessment as well. Appropriate comparison of photogrammetric surveys of a zone realised in different years allows identification of geometric changes occurring during the time interval in question (differential photogrammetry, Anzidei et al., 2000; Baldi et al., 2002, 2005).

This technique has many fields of application: for example, the study of changes in urban areas, farming activities and evolution of coastlines (Dolan et al., 1980; Overton and Fisher, 1996), checking glaciers (Kääb and Funk, 1999) and monitoring unstable slopes (Kääb, 2000).

Stereoscopic interpretation of two or more sets of aerial photographs taken over a sufficient- 
ly long time span (20-30 years) is the most effective and popular technique for the identification and morphological characterisation of landslides (multi-temporal landslide mapping) (van Westen and Getahun, 2003). This procedure assumes particular theoretical and applicative importance due to the fact that most landslide motion tends to take place within or very close to pre-existing landslide deposits. Therefore, knowledge of the location, type and distribution of landslides occurring over time in a territory, is an essential tool for forecasting future events.

It must nevertheless be pointed out that the reliability of stereoscopic interpretation strongly depends on the experience of the photo-interpreter. Thus, when studying landslide phenomena, it becomes important to utilise more quantitative techniques, such as analytic or digital photogrammetry, in association with photo-interpretation, which is intrinsically subjective and qualitative (Brunsden and Chandler, 1996; Lane et al., 1998).

Applicability of the two methods obviously depends on the availability of aerial photos of the territory, covering a sufficiently long time span. In this regard, it should be remembered that the first Italian national scale photogrammetric coverage, with classic pseudo-vertical photos $(23 \times 23 \mathrm{~cm})$, was conducted in 19541955 by the Istituto Geografico Militare (IGM). These photos, even though at a scale (1:330001:60000), may be a fundamental source of knowledge for the study of the temporal evolution of slope instability (there are also other old IGM surveys, at different scales, taken of individual portions of the territory).

Starting from 1970, in order to produce large scale maps (technical regional maps) and also in the context of specific projects (for example, monitoring of river valleys, glacier faces, slope landslides, etc.), many public administrations managed the realization of local photogrammetric surveys.

To assess the potential offered by the integration of qualitative and quantitative photogrammetric techniques in the study of landslides, we identified as test area an unstable slope located in the territory of the Municipality of Vergato, near the city of Bologna (Tuscan-Emilian Apennines, Italy) where in recent years a warning system was implemented installing inclinometers and piezometers, measuring pore water pressure and ground displacements by means of wire extensometers, GPS surveys, laser scanning and digital photogrammetric techniques (Mora et al., 2003; Bitelli et al., 2004; Pesci et al., 2004; Simoni et al., 2004; Dubbini and Zanutta, 2005).

This work presents the results of photo-interpretive analysis of four sets of aerial photos. Such analysis characterises the slope geo-morphologically, pointing out its temporal evolution based on morphological changes identified in the available stereoscopic models.

A quantitative analysis of the landslide movements was performed comparing multitemporal DTMs produced with an analytical plotter (DIGICART 40, Officine Galileo), and a digital photogrammetric workstation (Helava System).

\section{Photo interpretation investigations of the landslide phenomena}

The territory of the Municipality of Vergato contains numerous slopes affected by landslides, many of which are currently active. Due to its geological-geomorphologic structure and types of land use and settlement, this area may be considered highly representative of the mountainous territory of the Emilia-Romagna Region, for which recent studies claim that of more than 32000 landslides identified and mapped, approximately $26 \%$ are to be considered «active» (Bertolini and Pellegrini, 2001).

Table I. Main characteristics of aerial photos utilised for production of multi-temporal map of landslides in instudy area.

\begin{tabular}{ccccc}
\hline \hline Agency & Photo scale & Type & Year & Month \\
\hline GAI, IGMI & $1: 60000$ & B\&W & 1954 & June \\
$\begin{array}{c}\text { Emilia-Romagna } \\
\text { Region }\end{array}$ & $1: 20000$ & B\&W & 1971 & - \\
$\begin{array}{c}\text { Emilia-Romagna } \\
\quad \text { Region }\end{array}$ & $1: 17000$ & Colour & 1976 & May \\
$\quad \begin{array}{l}\text { Alifoto Srl } \\
\text { for ENEL Hydro }\end{array}$ & $1: 4400$ & B\&W & 2000 & April \\
\hline
\end{tabular}


This work examines the instability phenomena affecting the slope on the right bank of the Reno River, below the Vergato-Piandisetta road in the vicinity of Cà di Malta and Cà del Bosco (Bologna). This slope is composed of terrains pertaining to the Scaly Clay Complex: their poor mechanical properties make it one of the most unstable geological complexes in the entire Apennine territory.
A multi-temporal landslide map was produced for this area by means of a detailed interpretive study of photos taken during four photogrammetric flights, from 1954 to 2000, with photographic scale ranging from 1:60000 to approximately 1:4400 (table I; fig. 1a-d).

The multi-temporal landslide map was produced by means of careful photo-interpretive examination of all the available aerial photos,
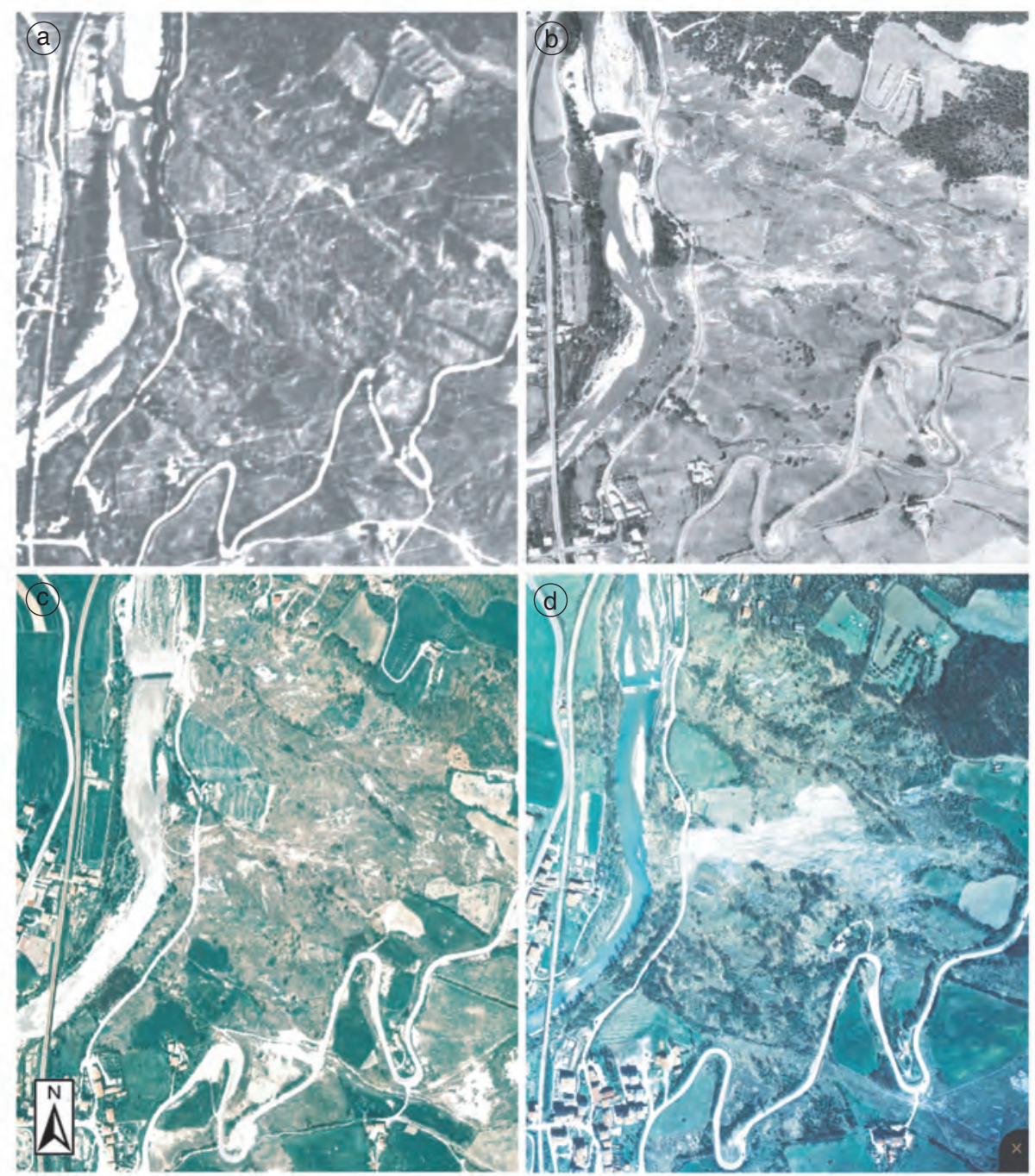

Fig. 1a-d. Multitemporal aerial photos details concerning landslide bodies (Municipality of Vergato, Bologna, Tuscan-Emilian Apennines, Italy; $\left.\phi=44^{\circ} 17^{\prime} 25^{\prime \prime} \mathrm{N}, \omega=11^{\circ} 07^{\prime} 16^{\prime \prime} \mathrm{E}\right)$ : a) 1954; b) 1971; c) 1976; d) 2000. 
using a stereoscope with continuous 2-20X zoom. Interpretation began with an analysis of the 1954 aerial photos, in which it was possible to identify both large-scale landslides (mostly old and relicts) and smaller landslides, generally more recent. The aerial photos from the other flights were then analysed, separately and in combination with those from 1954, comparing similarities and differences in morphology in each portion of the slope under study. The landslides were classified on the basis of estimated depth, type of movement (slip-flow and flow) and relative age (old or recent). This last parameter was deduced from the degree of morphological «freshness» that the instability presented in each set of photos.
The photo-interpreted landslides were first redrawn on map at 1:4400 scale and then digitised and stored in a GIS for data display and analysis.

Figure 2 shows the distribution of the landslides identifiable on the 1954 photos. The oldest landslides may be classified as slip and slipflow within which (as described below) numerous landslides identified in the flights conducted from 1954 to 2000 have developed.

The main landslide is a deep slip, mostly relict, with a surface area of about $160000 \mathrm{~m}^{2}$ and average slope of $15^{\circ}$, extending from $320 \mathrm{~m}$ a.s.l, below the Vergato-Piandisetta road, until the Reno River to $185 \mathrm{~m}$ a.s.l. Over time, this landslide underwent partial reactivations with

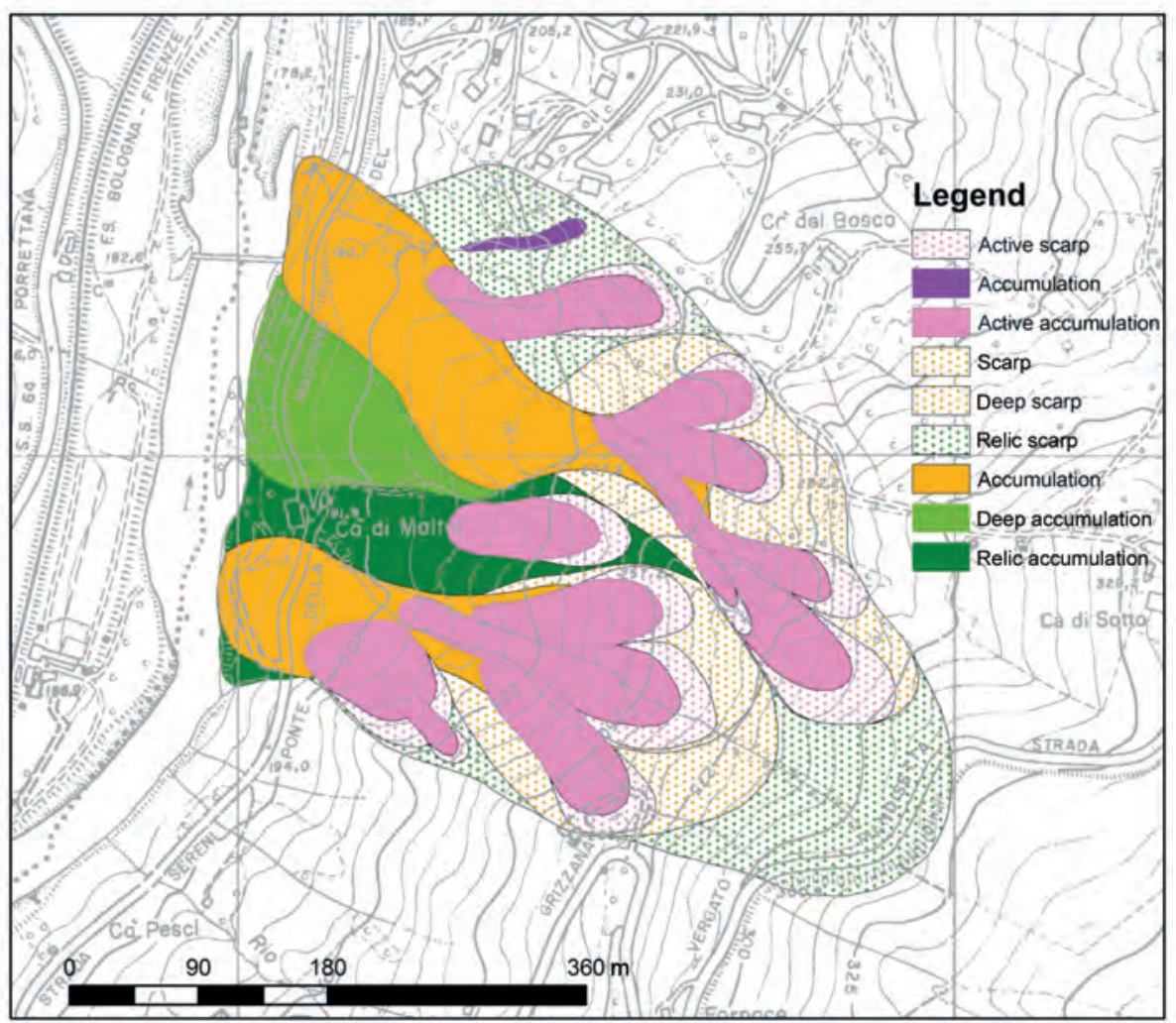

Fig. 2. Distribution of old or very old landslide bodies identified in 1954 aerial photos, classifiable as slip and slip-flow, with elements of activity. 
movements of various magnitude that masked or cancelled some of the features of the main landslide, in some cases making it difficult to identify. The alimentation area, shown by a marked concavity on the slope, is characterized by a main scarp whose arched shape is recognisable at various points, and continues for more than a kilometre. Locally, the slope's concavity is more complex, marked by later landslides that created sudden changes in dip. The accumulation zone shows general longitudinal and transverse convexity to the slope, which becomes more accentuated at the foot, where the Reno River was slightly deviated toward the west for more than $350 \mathrm{~m}$. Two old slip-flows, with a characteristic narrow, elongated accumulation shape which then fans out at the foot of the landslide, have developed at the sides of this relict landslide.

The phenomenon that has developed on the right side of the main slip (hereafter called «Cà del Bosco») presents a complex and deep scarp area that reduces almost to a funnel around 225 $\mathrm{m}$ of high. On the other hand, the deposit presents a sharply lobed convex shape on which several generations or pulsations of landslides may be noted, superimposed on the accumulation of the old main slip.

The landslide that developed on the left side of the main slip (hereafter called «Cà di Malta») presents less evident morphological characteristics. Its scarp area is not very accentuated and is highlighted by a large concavity, while the deposit presents a marked lobe at the foot of the landslide that further reduces the Reno River channel by a few meters.

Figure 2 also shows distribution of the landslides classified as slip and slip-flow, recent and/or active, traceable to around 1954. In the photos, these landslides show clear evidence of morphological «freshness», demonstrating movements in evolution. These movements are of low or medium magnitude, with extensions ranging between 1000 and $15000 \mathrm{~m}^{2}$. They are located almost exclusively in the scarp areas of the Cà del Bosco and Cà di Malta landslides, without ever pushing down to the base of the slope.

The landslides which occurred during the period 1954-1971, are essentially two deep slipflows extending from $40000 \mathrm{~m}^{2}$ to $70000 \mathrm{~m}^{2}$, classifiable as reactivations of the previous Cà del
Bosco and Cà di Malta landslides, within and at the borders of which small landslides no larger than $5000 \mathrm{~m}^{2}$ may be seen.

In the period 1954-1971, at least two generations of movement may be seen for the Cà del Bosco landslide. The first involved the uppermiddle part of the previous instability, without reaching the base of the slope, whose foot appears changed at several points, the left side more convex downhill and advanced by about $20 \mathrm{~m}$ compared to its appearance in the 1954 photo. The second was a reactivation of the previous landslide. The scarp has receded by about $100 \mathrm{~m}$, reaching almost near the VergatoPiandisetta road, while the deposit has reached the base of the slope, very probably blocking the valley road. The activity of this movement is demonstrated by an irregular surface with mounds, landslips troughs, and numerous tension fractures open both longitudinally and transversely. The medium-high section of the flow (from high 250 to $220 \mathrm{~m}$ ) is winding, with a sharply depressed and concave transverse profile developing within the centre of the valley. As evidence of the rapid flow of material, along the sides of this section of the flow one may clearly see levees that form crests a few meters high, extending for over $200 \mathrm{~m}$ in length. The foot of the flow is clearly convex, with an irregular surface lobed by pronounced bumps.

In the Cà di Malta landslide area, the instabilities occurring in the period 1954-1971 reactivated the entire old body with slip-flow movements, considerably reducing the scarp and advancing its foot by about $20 \mathrm{~m}$ to within the Reno River bed. Specifically, the border has receded by over $50 \mathrm{~m}$, touching the head of the Cà del Bosco landslide. The main scarp has steps of more than $10 \mathrm{~m}$ and extends continuously, mainly along the left side of the landslide for about $200 \mathrm{~m}$. The deposit has an irregular surface, with a generally convex shape that has been remodelled and regularised in the centre section as the result of drainage works with channels and surface drains running rectilinear or transverse to the slope. As shown in the 1971 photos, the foot of the landslide is limited by blocks aligned in the Reno River bed, seen for the entire width of the landslide front at about $20 \mathrm{~m}$ from the bank, which precisely in this sec- 
tion is eroded and receded due to lateral undermining. In addition, the road's path has been altered along this section of the landslide, making it straighter than it was in 1954.

The movements which occurred in the period 1971-1976, identifiable in the colour aerial photos taken in 1976, are mainly due to small flows or slip-flows occurring in the centre channel of the Cà del Bosco flow or in the scarp area of the Cà di Malta landslide. On the border of this latter landslide, it is interesting to note the presence of an anthropic intervention that caused about 20 $\mathrm{m}$ of stripping and the creation of a rise of more than $1000 \mathrm{~m}^{2}$ halfway up the hill. It is important to point out that the most extensive reactivation began precisely at the site of such work, as seen on the 2000 photos.

Lastly, the landslides occurring between 1976 and 2000 were essentially a total or partial reactivations of previous Cà del Bosco and Cà di
Malta landslides, with deep slip-flows measuring between 0.5 and 4.0 ha and small flows with surface area not exceeding $0.5 \mathrm{ha}$. The most evident reactivations might be traceable to movements occurring in October 1996 following long, heavy precipitation, or in November 1998 in the absence of exceptional rains.

These photos show the Cà del Bosco landslide reactivated at its top, with the formation of a few slip-flows, the most evident of which is the one formed from the right side of the scarp at $290 \mathrm{~m}$ high near a few farm annexes of Cà di Sotto homes. The alimentation area of this landslide is characterised by a sharp depression, bounded by a main scarp of about $20 \mathrm{~m}$ and by a series of secondary scarps and tiers. The deposit is channelled in the medium-high section of the old 1971 flow, which is topographically depressed and concave, filling it with more than $10 \mathrm{~m}$ of sediment (estimated thickness). The

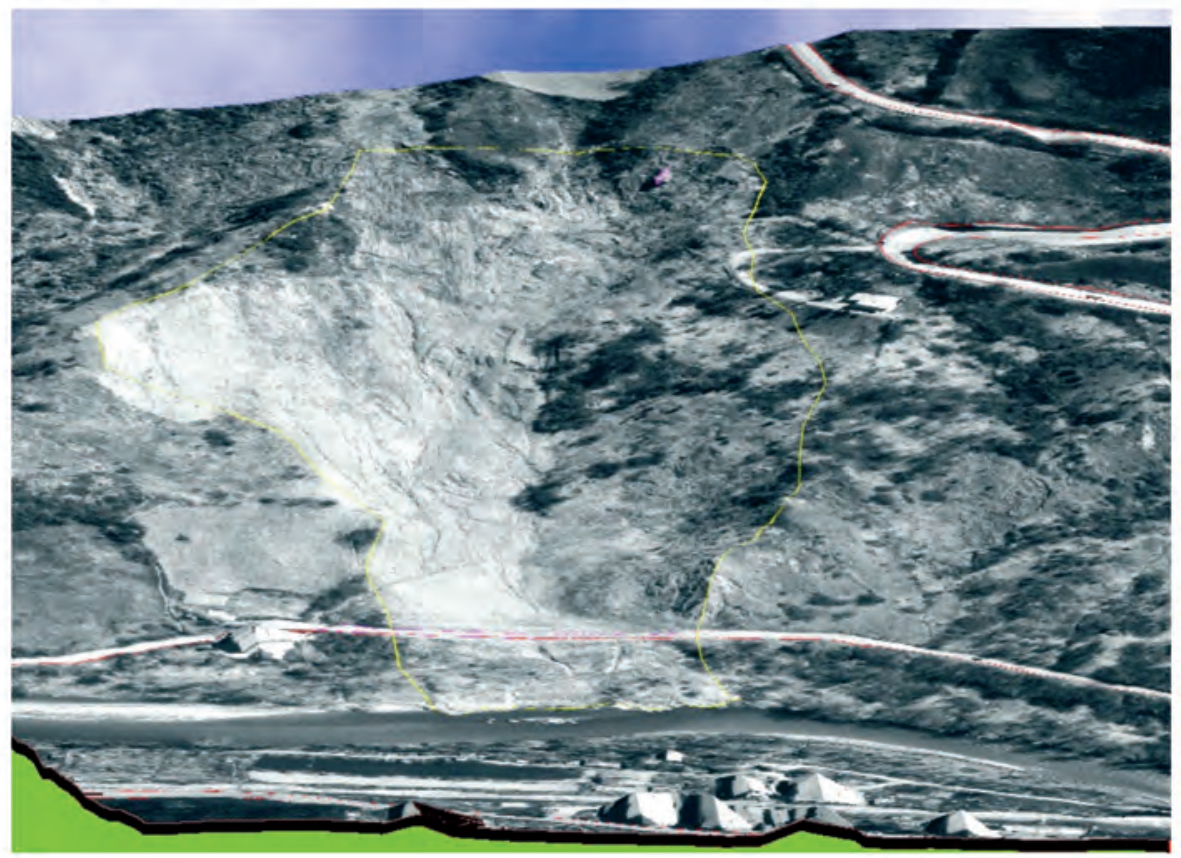

Fig. 3. Three-dimensional perspective view of southern portion of slope under study, obtained by projecting the 2000 digital orthophoto onto the corresponding $2 \times 2 \mathrm{~m}$ DTM (heigh exaltation: $30 \%$ ). The image represents a vector/raster result which has metric characteristics, coming from photogrammetric restitution. The border of the Cà di Malta landslide is indicated with a yellow line; red lines show local roads. 
flow stops at 225 high, where it forms a topographically pronounced and prominent lobe.

In the area of the Cà di Malta landslide (fig. 3 ), the instabilities occurring in the period 19762000 reactivated most of the old 1971 body, with slip-flow and flow movements, considerably pulling back the scarp precisely at the site of the anthropic intervention observed during the 1976 flight. At this point, the border has receded by about $100 \mathrm{~m}$, pushed back as far as the VergatoPiandisetta road and creating, once again, a sharp depression with a main scarp of over $20 \mathrm{~m}$. The other movements noted in the scarp area or at the borders of the Cà di Malta landslide also show a distribution of retrogressive activity, but with more limited retrograding of about $20-30 \mathrm{~m}$. These movements are clearly seen in the medium-high part of the slope, where they all meet at around $200 \mathrm{~m}$ high. On the other hand, the medium-low sector of the slope has been heavily remodelled by work done to reinforce the landslide, with drainage and reprofiling of the slope. In these cases, man's cancellation of shapes makes it very difficult, if not impossible, to define and map the real extent of the movement. Nevertheless, careful examination and comparison of the last two aerial photo flights has provided elements useful for defining and extending the landslide up to the Reno River. The hypothesis that the landslide may have reached the valley is supported by bibliographic information (Mora et al., 2003) reporting partial obstruction of the waterway following the reactivation taking place in October 1996.

\section{Photogrammetric investigation of the landslide phenomena}

In order to define the shape and position of objects or portions of land by means of photogrammetry, it is necessary to reconstruct the geometric relationships on which the images were taken.

The cameras used in photogrammetry produce photos, which, with sufficient approximation, may be considered central perspectives of the photographed object, that is all the rays going from the image to the object pass through the perspective centre.
The basic mathematical model used to convert from a two-dimensional system (photo) to a three-dimensional system (object) is expressed by well-known colinearity equations (Kraus, 1997) expressing that the perspective centre, the object points, and the image points are lying on the same projective straight lines.

To transform the image coordinates in the corresponding object coordinates, at least two photos of the same object and the nine orientation parameters internal (IOP), and external (EOP) are needed. As known, in traditional photogrammetry, IOPs are determined in laboratory by means of camera calibration procedures; EOPs can be determined by spatial resection by using known Ground Control Points (GCPs), visible on the photos, whose coordinates are measured in the image reference systems.

Orientation parameters defining the camera station coordinates and the orientation angles are often unavailable for historical aerial photos. Therefore, to produce the 3D model of the area, it is necessary to adopt an unconventional approach that gives results less precise than the rigorous one. The aerial photos can be considered taken by non metric cameras, and a selfcalibration procedure can then be performed (self-calibrating bundle block adjustment), based on the availability of a sufficient number of GCPs. Generally this method is not applicable because it is difficult to find enough GCPs measured at the same time of the flight.

Since large-scale maps of the zone are available, one solution may be to detect the GCPs from them (Chandler et al., 1988a,b; Chandler and Brunsden, 1995), even if a variety of problems may be encountered: the maps may have been drawn from aerial photogrammetric surveys prior or subsequent to the one being analysed; it is difficult to assess the real error to be assigned to the coordinates of the points measured on the map (for example, altitudes derived by interpolation from level curves); it is often very difficult to identify equivalent points, i.e. the search for map GCPs on stereoscopic models.

The method adopted in this paper to solve the orientation problem and to co-register the multi-temporal three-dimensional models, is based on identification of a large number of 
points, located outside the landslide bodies, and visible on multi-temporal stereoscopic models.

As mentioned above, three sets of historical aerial photos (from 1954, 1971 and 1976) plus the large-scale photos obtained in 2000 with a calibrated aerial camera, are available for the area under study. Simultaneously with the 2000 flight, a large number of ground points (GCPs), well distributed in the zone, were measured in the frame of a GPS campaign (Mora et al., 2003).

The procedure consisted of four steps:

i) Orientation of the 2000 photos.

ii) Identification of natural points on the 2000 stereoscopic model and editing of precise monographs.

iii) Photogrammetric measurement of $3 \mathrm{D}$ coordinates of such points in the 2000 reference system and identification of the same points on the old photos.

iv) Computation of EOPs of various historical models using GCPs derived from the 2000 survey.

The GCPs were selected outside the landslide bodies, giving the preference to artificial elements (for example, buildings), homogeneously distributed in the area.

The GCPs selection procedure was based on assessment of space resection program for the historical images, rejecting, with an iterative approach, points showing high external orientation residuals respect to a theoretical value coming from the scale of the images. Obviously, the ability to correctly identify points unusable for support the orientation is greater if a large number of points is examined.

At the end of the procedure, all of the «historical» stereoscopic models were oriented into an absolute reference system derived from the 2000 survey, making it possible to perform comparisons between the DTMs, as later discussed.

The orientation and plotting steps for the stereoscopic models were first performed with a DIGICART 40 (Officine Galileo) analytical plotter. Because no calibration certificates were available for the cameras used on the historical flights $(1954,1971,1976)$, the internal orientation and image coordinates refinement procedure was applied using the focal length pressed on the films, ignoring effects due to lens distortion, non-planarity of the film, and non alignment of the principal point with its theoretical position. Correction was made for the earth curvature.

Relative orientation was performed using a very large number of points distributed uniformly through the entire area of the models covering the landslide zone. Absolute orientation was performed with the procedure described above. Once the orientation parameters were known, it was possible to acquire three-dimensional data for the slope under study. DTMs of the zone with grids of different size $(2 \times 2 \mathrm{~m}, 4 \times 4 \mathrm{~m}, 8 \times 8 \mathrm{~m})$ were created from the four models in order to reveal any mass movements and to simultaneously determine the best cell size for describing morphological details.

In assessing the degree of uncertainty of the results, it has to be considered that an unconventional method was used to solve the orientation problem, and that the available images are characterized by different scale, ranging from $1: 60000$ to $1: 4400$.

This fact created many problems:

1) Errors of a 1:60000 scale model are greater than those of a 1:4400 scale model.

2) It is difficult to identify homologous points to use as reference (especially between 1954 and 2000), due to the different resolution of the photos and to the lack of useful elements in the territory. The search procedure was conducted by dividing the common zone into subareas in which a large number of homologous points were then catalogued. Analysis of residuals deriving from the external orientation procedure revealed, at any step, the points that could be considered useful for this purpose, because assumed not subject to movements.

3) In the 1:4400 photos points cover the entire observed area, whereas in the lower-scale images they are concentrated in a small zone of the model.

In the absence of data from other sources, simple approaches such as computation of variance propagation and empirical assessments of the quality of results were utilised to estimate the precision of DTMs acquired in stereoscopy and therefore to evaluate the significance of the measured deformations.

Assuming the so called Normal Case, in order to simplify the colinearity equation (the camera axes are considered parallel to each oth- 
Table II. Characteristics of available photogrammetric surveys and theoretical assessment of level error, assuming $\sigma_{\mathrm{P} \xi}=$ Standard Deviation (SD) in measurement of horizontal parallax $= \pm 10 \mu \mathrm{m}$ and, for pre-2000 surveys, $\sigma_{c}=\mathrm{SD}$ of focal length of camera $= \pm 10 \mu \mathrm{m}$. Values expressed in meters.

\begin{tabular}{ccccc}
\hline \hline Year & 1954 & 1971 & 1976 & 2000 \\
\hline $\begin{array}{c}\text { Mean flight } \\
\text { heigh (m) }\end{array}$ & 9509.9 & 3376.8 & 2973.9 & 1011.3 \\
$\begin{array}{c}\text { Nominal } \\
\text { focal length } \\
\text { Base line }\end{array}$ & 0.154 & 0.152 & 0.153 & 0.152 \\
$\begin{array}{c}\text { Mean topographic } \\
\text { heigh (m) } \\
\text { Mean }\end{array}$ & 300.00 & 300.00 & 300.00 & 300.00 \\
$\begin{array}{c}\text { scale factor } \\
\text { Mean } B / Z\end{array}$ & 0.62 & 0.59 & 0.43 & 0.51 \\
$\sigma_{Z}$ & \pm 1.45 & \pm 0.58 & \pm 0.72 & \pm 0.18 \\
\hline
\end{tabular}

er and perpendicular to the base line) and applying the law of variance propagation, considering both the error assigned to measurement of horizontal parallax (assuming $\sigma_{\text {Parallax }}= \pm 10 \mu \mathrm{m}$ ) and, only for the pre-2000 surveys, the camera focal length (assuming $\sigma_{\text {Camera }}= \pm 10 \mu \mathrm{m}$ ), we derived a theoretical mean square deviation value expected for $Z$ coordinate (elevation); if $B$ is the distance between the camera's centres relative to two stereo pairs, as known, for usual base-ratios $(B / Z>0.5)$ this is generally greater than the planimetric ones. Table II shows the main flight data and the value of theoretical $\sigma_{Z}$.

Table II shows a clear correspondence between the mean standard deviations and the scale factors of the photos: the 1954 survey shows theoretical errors of a higher magnitude than those from 2000. Moreover 1971 presents theoretical errors that are slightly lower than those from 1976 data; this is due to the base-ratios values. Obviously, the error related to uncertainty in collimation of natural points must be added to the $\sigma_{Z}$ theoretical one.

A measurement repeatability test was performed: DTMs on sample area were generated in different periods, by the same operator, with the same analytical instrument, in semi-automatic mode. The comparison of such results (see table III) shows good repeatability of the measurements and confirms the close correlation between image scale factor and errors.

Considering the above observations as a whole and the values listed in table II, and in order to adopt a simple and homogeneous criterion, we have chosen $1 \mathrm{~m}$ as the significant range of movement in DTMs comparisons, from 1971 up to 2000. The point differences lying within such interval have therefore been considered non-indicative of deformation due to landslide movement. If the 1954 DTM is used for comparisons, the significant range assumed is $2 \mathrm{~m}$.

To guarantee the quality of data to be used in this research, the above-described photogrammetric method was performed using both an analytical plotter and semi-automatic or manual vector procedures, with a significant amount of work of an expert operator, and the digital photogrammetry technique for the automatic generation of terrain models and orthophotos. In particular, in addition to the photogrammetric process performed by analytical stereoplotter, the 2000 survey images were used to generate a DTM with a high-level digital photogrammetric workstation (Helava System), adopting semi-automatic and automatic procedures.

The films were scanned with a RasterMaster (Wehrli \& Associates Inc., NY, U.S.A.) photogrammetric scanner at a 1000 dpi resolution,

Table III. Measurement repeatability test.

\begin{tabular}{lccc}
\hline \hline & 1971 & 1976 & 2000 \\
\hline No. points & 214 & 214 & 850 \\
Standard deviation (m) & 0.68 & 0.59 & 0.36 \\
\hline
\end{tabular}

Table IV. Characteristics of images acquired with photogrammetric scanner.

\begin{tabular}{cc}
\hline \hline Year of the survey & 2000 \\
Photo scale & $1: 4.400$ \\
Panchromatic film & Colour \\
Image resolution $(\mu \mathrm{m})$ & 24 \\
Ground resolution $(\mathrm{cm})$ & 12 \\
File image dimension $(\mathrm{Mb})$ & 240 \\
\hline
\end{tabular}




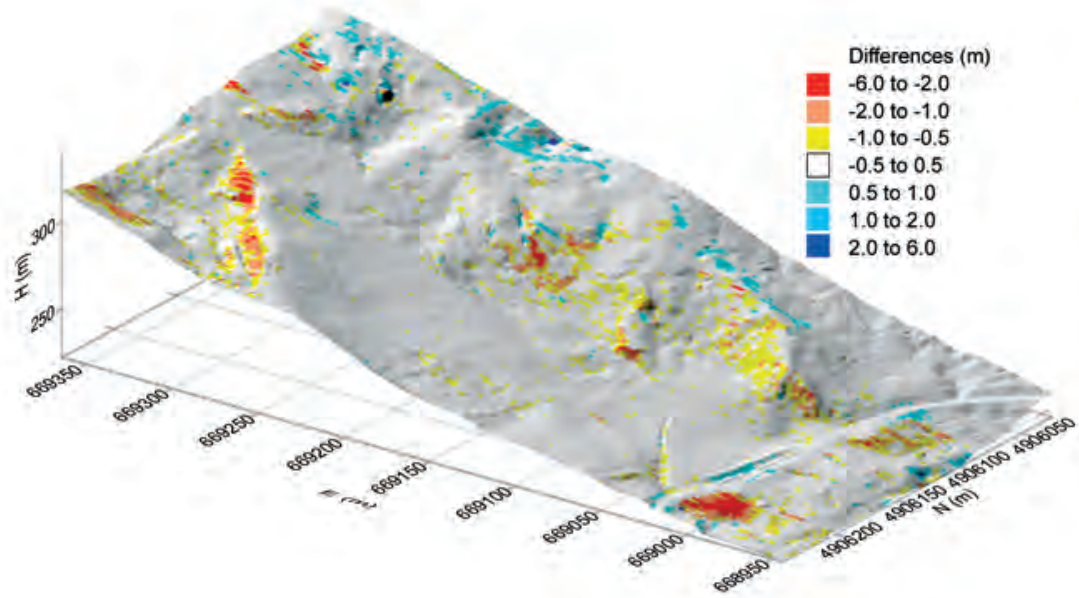

\begin{tabular}{|c|c|}
\hline No. points & 20780 \\
\hline Min & -5.40 \\
\hline Max & 3.80 \\
\hline Mean & -0.15 \\
\hline $\begin{array}{l}\text { Standard } \\
\text { deviation }\end{array}$ & 0.42 \\
\hline \multicolumn{2}{|c|}{} \\
\hline Range & $\%$ \\
\hline Min $\div-2$ & 0.66 \\
\hline$-2 \div-1$ & 2.58 \\
\hline$-1 \div-0.5$ & 8.09 \\
\hline$-0.5 \div 0.5$ & 85.76 \\
\hline $0.5 \div 1$ & 2.56 \\
\hline $1 \div 2$ & 0.33 \\
\hline $2 \div$ Max & 0.03 \\
\hline
\end{tabular}

Fig. 4. Comparison between the reference DTM (DIGICART $2 \times 2 \mathrm{~m}$ ) and DTM automatically generated with Helava system; colour classified differences are shown overlapped the shaded relief model.

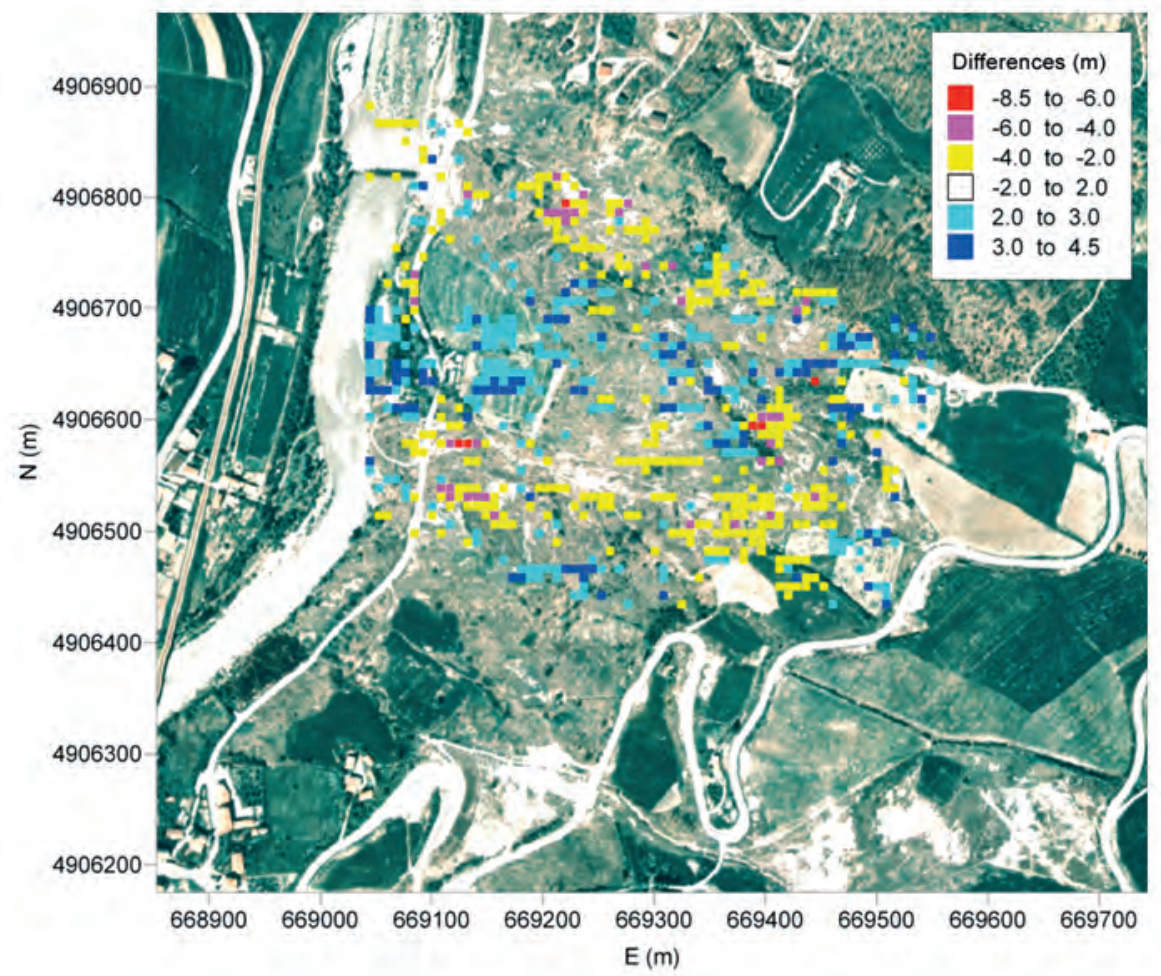

Fig. 5. High differences obtained from 1976 and 1954 surveys. Differences (in meters) superimposed on 1976 ortho-photo are indicated by different colours. 


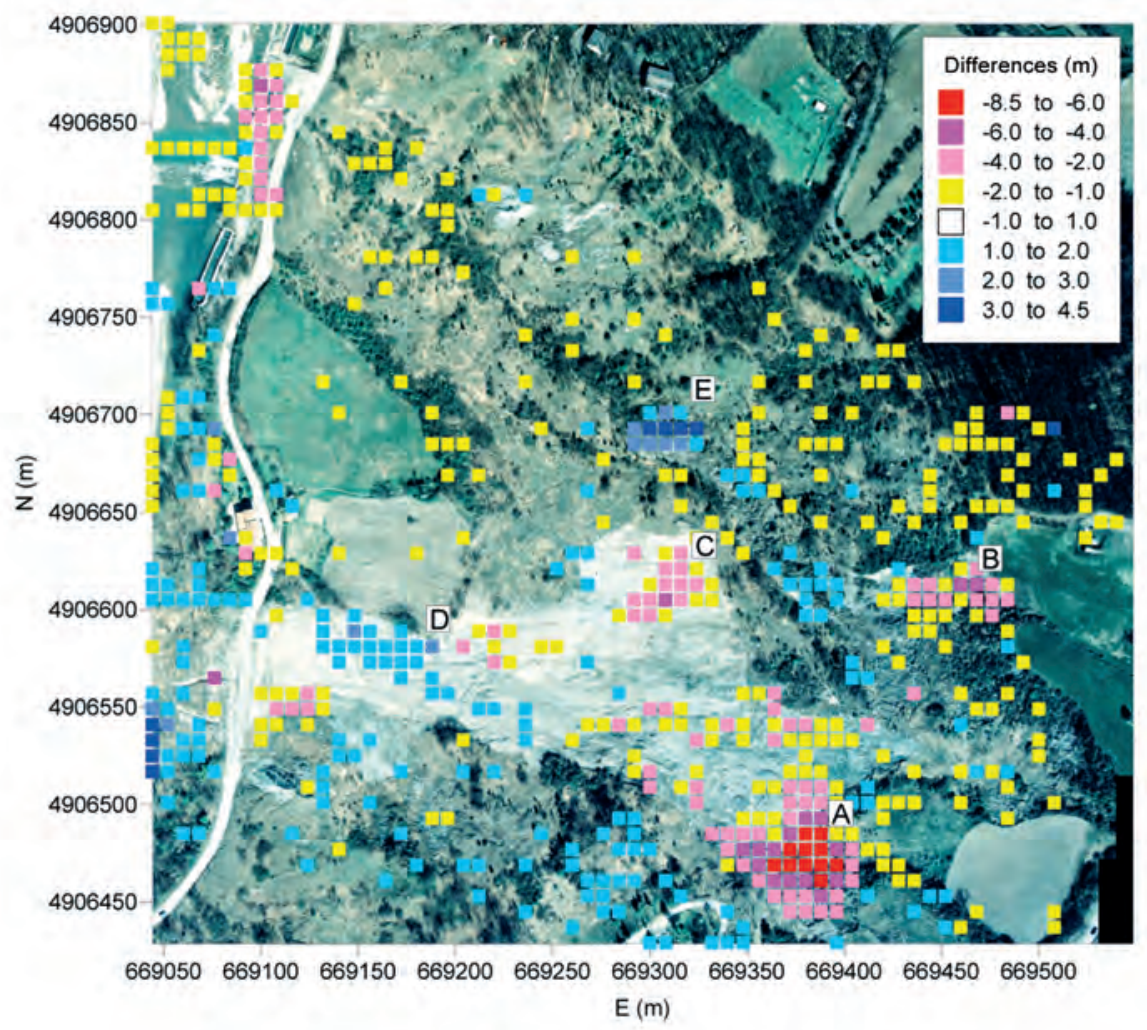

Fig. 6. High differences between the $8 \times 8 \mathrm{~m}$ DTMs obtained from 2000 and 1976 surveys. Differences (in meters) superimposed on 2000 orthophoto are indicated by different colours.

sufficient to guarantee a high level of detail (ground pixel size about $12 \mathrm{~cm}$; table IV).

The DTM was firstly generated automatically, with post-editing by the operator to correct errors deriving from the correlation procedure; editing consisted mainly of manual insertion of breaklines into incorrect zones, with consequent local recalculation of the surface area.

The DTM automatically generated by digital photogrammetry was then compared to the one generated by the analytical plotter; fig. 4 shows the differences between the two models. It may be seen that for $96.5 \%$ of the points, the difference between the two models is within an interval of $\pm 1 \mathrm{~m}$, and that the largest differences are localized mainly in zones with complex morphology and shadowed areas.
In addition, together with DTM and classic vector products, a digital orthophoto has been produced, to give a photographic representation, with metric characteristics, of the situation in a landslide area at a defined time. Modern digital photogrammetry and GIS programs can also generate highly effective three-dimensional views that combine the expressive potentials of ortho-photos and three-dimensional data of DTM. Figure 3, generated with ErMapper software, refers to the 2000 orthophoto.

The comparison of multitemporal DTMs, performed without the use of interpolators, allowed us to quantify the geometric variations occurring as a result of evolution of the landslide. The two following figs. 5 and 6 graphically show the results of comparisons of the 1954, 1976 and 


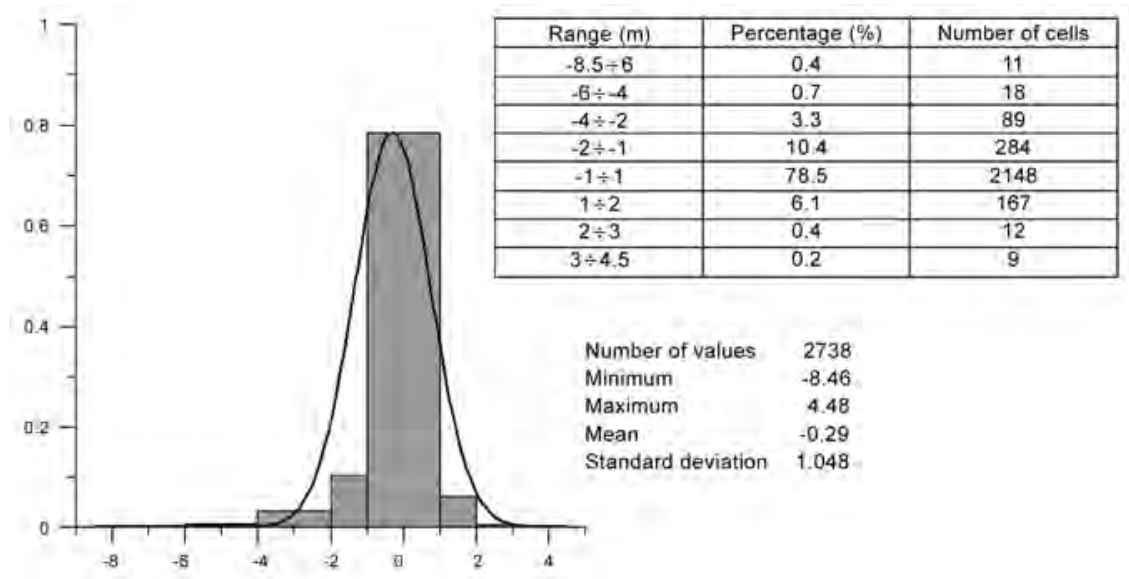

Fig. 7. Statistic of differences between 2000 and 1976 DTMs.

2000 surveys; the movement determined for individual cells is highlighted in colour. For better legibility of the figures, the digital orthophotos generated for the 1976 flight and the 2000 flight, respectively, have been used.

Figure 5 shows the result of the comparison between DTMs from 1954 and 1976, with $8 \times 8 \mathrm{~m}$ grid resolution. Figure 6 refers to differences relative to the period 1976-2000, for which a histogram of heigh differences is shown in fig. 7.

Other comparisons, for example those involving the 1971 model, are not discussed in this paper, due to the lack of further information with respect to the presented data.

\section{Landslide map and differential DTM comparison}

Comparative analysis of the multi temporal DTMs indicate that the landslide reactivated in the time interval 1954-1971, while in the following period (1971-1976) the slope was almost inactive. The movements involved both the Cà di Bosco and Cà di Malta landslide bodies (fig. 5). The alimentation area is characterized by a main scarp with arched shape, locally complex, that is recognisable at various points. The movements observed in this area confirm a distribution of a moderate retrogressive activity along the left side of the landslide area, as detected by means of the photo interpretation investigations. The amount of material moved is less than assumed by qualitative inspection.

The time interval 1976-2000 was characterized by a more important reactivation of the landslide in 1996, after a long period of relative inactivity (Mora et al., 2003). Subsequently, in 1998, a small rotational slide involved the upper part of the Cà di Malta main body. Part of the effects of these movements, principally at the foot of the landslide, were remodelled by human activity in the frame of consolidation and drainage works.

The results of natural and anthropic activities are shown in fig. 6. The largest mass movements occurred at the scarp areas of the Cà di Malta and Cà del Bosco landslides, where negative values ranging between 2 and $8 \mathrm{~m}$ are present in fairly limited areas. On the other hand, the most significant uplifts are also localized in very restricted areas, mainly at the foot of the landslides, and they do not exceed $4.5 \mathrm{~m}$. Over an area of about $15 \times 10^{4} \mathrm{~m}^{2}$ the volumetric analysis gives a negative variation of $75 \times 10^{3} \mathrm{~m}^{3}$ and an accumulation of about $25 \times 10^{3} \mathrm{~m}^{3}$.

Observing the statistic of the residual concerning areas assumed to be stable (differences $<1.00 \mathrm{~m}$ ) and assuming systematic errors due to model orientations of about $20 \mathrm{~cm}$ for the 1997- 
2000 data, the estimation of the volumes is given with the precision of $20 \%$.

The difference between the depletion and accumulation volumes is principally due to the removal of material along the river and above the road at the foot of the slope.

For more precise analysis of the relationships between the high residuals and the 1976 and 2000 landslides map, fig. 6 shows (with coloured rectangles and letters, points $\mathrm{A}$ to $\mathrm{E}$ ) the areas in which the most significant surface lowering or uplifts occurred. The significant topographic changes may be seen at the slipflow that develops along the left side of the Cà di Malta landslide.

Point A corresponds to an area of about 4000 $\mathrm{m}^{2}$, with the largest negative variations, and coincides with the landslide alimentation area, quantitatively defining the extent of the depression and the distribution of the slopes of the scarp area. Degradation values increase rapidly toward the centre of the area. This depressed area has arched borders located precisely at the main scarp and at the head of the landslide.

At point B, the scarp is clearly shown in an area of the differentials map in which major level degradations may be observed. The values presenting the most significant variations (between 2 and $4 \mathrm{~m}$ ) correspond to the alimentation area of the 2000 slip-flow, which caused a sharp depression bordered by a distinct main scarp and repeated secondary scarps and terracings.

Point D shows local uplifts. This zone coincides with the foot of the landslide, where the accumulation is elongated and slightly lobed.

Other significant topographic changes may be seen at points $\mathrm{B}$ and $\mathrm{E}$, along the slip-flow that develops starting from the right side of the Cà del Bosco landslide.

Point E shows an area in which the differential map presents a distinct uplift of about $4 \mathrm{~m}$. This area corresponds to the point where the landslide stopped, generating a lobe-shaped accumulation at the foot.

Significant topographic changes may also be seen at point $C$ where the slope was remodelled by man for reinforcement and drainage works.

Lastly in the area at the foot of the landslide the topographic changes shown on the residuals map are not traceable to landslides, but rather to anthropic activity. In particular, the degradations are due to construction of a short section of road leading to the Reno River, while the uplifts are caused by levelling of the slope by man to reclaim the foot of the Cà di Malta landslide.

\section{Conclusions}

Stereoscopic analysis of four sets of aerial photos, taken over a time span of almost 50 years, allowed reconstruction of the complex sequence of landslide movements occurring on the slope under study. The 1954 photos, despite the low-scale (1:60000), provided significant evidence of a slip-flow-type landslide body affecting the entire slope. This event may be considered the primary cause of all of the subsequent movements, which are therefore to be understood as partial reactivations of such landslide. Of these, the Cà di Bosco and Cà di Malta landslides are the most extensive phenomena.

The event cannot be dated on the basis of available data. Nevertheless, studies conducted in the Apennine area have demonstrated that most of the large landslides are hundreds or even thousands of years old (Bertolini and Pellegrini, 2001).

A quantitative analysis of the territory has been obtained with an appropriate comparison of photogrammetric surveys of the zone realised in different years, allowing identification of geometric changes occurring during the time interval in question. The absence of fundamental information on geometric parameters of the images has been overcome by adopting an unconventional method to co-register all the datasets in the same reference frame, based on the detection of homologous points in the multi temporal models. The areas and the amount of masses involved in the reactivations of the landslides have been estimated, giving a contribution to the morphological interpretation of the landslide deformation phenomena in the last years.

The availability of historical stereoscopic images assumes particular importance in the study of long time span phenomena, which produce surface deformations of the Earth. Furthermore the possibility of adopting the digital photogrammetry approaches will yield faster and higher 
resolution results, at lower costs with respect to the analytical analysis. The availability of highresolution satellite images which may become competitive with small-medium scale aerial photos will lead to the low-cost creation of image archives with repetition intervals that depend on the temporal resolution of the satellite.

\section{Acknowledgements}

The work was partially financed by the PRIN2003 Italian National Research Project «Tecnologie innovative per la previsione, il controllo e la mitigazione dell'impatto delle emergenze ambientali» (Nat. Resp. Prof. Sergio Dequal). The authors wish to thank to Prof. Luca Vittuari and Dr. Francesco Mancini for their support in data processing.

\section{REFERENCES}

AnZidei, M., P. BAldi, F. Chiocci, M. Marsella, E. MarTORELLI and A. ZANUTTA (2000): Integrazione tra un rilievo aerofotogrammetrico e batimetria swath: il DTMM del versante orientale e meridionale dell'Isola di Palmarola (Lazio), Boll. Soc. Geol. Ital., 119, 767-775.

Baldi, P., G. Bitelli, A. CARrara and A. ZanutTa (2002): Detecting landslide long term movements by differential photogrammetry, in Proceedings of the European Geophysical Society, XXVII General Assembly, 21-26 April, Nice, France.

BAldi, P., M. FABris, A. Marsella and R. Monticelli (2005): Monitoring the morphological evolution of the Sciara del Fuoco during the 2002-2003 Stromboli eruption using multi-temporal photogrammetry, ISPRS J. Photogramm. Remote Sensing, 59 (4), 199-211.

Bertolini, G. and M. Pellegrini (2001): The landslides of the Emilia Apennines (Northern Italy) which resumed activity in the 1994-99 period and required Civil Protection interventions, Quad. Geol. Appl., 8 (1), 27-74.

Bitelli, G., M. Dubbini and A. ZanutTa (2004): Terrestrial Laser Scanning and Digital Photogrammetry techniques to monitor landslide bodies, in Proceedings of ISPRS, 12-23 Luglio 2004, Istanbul, Turkey.

BRUNSDEN, D. and J.H. CHANDLER (1996): Development of an episodic landform change model based upon the Black Ven mudslide, 1946-1995, in Advances in Hillslope Processes, edited by M.G. ANDERSON and S.M. Brooks (J. Wiley, Chichester, U.K.), 869-896.

ChANDLER, J.H. and D. BRUnSDEN (1995): Steady state be- haviour of the Black Ven mudslide: the application of archical analytical photogrammetry to studies of landform change, Earth Surf. Processes Landforms, 20, $255-275$

Chandler, J.H. and M. Cooper (1988a): Monitoring the development of landslides using archival photography and analytical photogrammetry, Land Miner. Surveying (Royal Institution of Chartered Surveyors), 6, 576-584.

CHANDLER, J.H. and M. COOPER (1988b): The extraction of positional data from historical photographs and their application in geomorphology, Photogramm. Rec., 13 (73), 69-78.

Dolan, R., D. HAYdEn, D. MAY and S. MAY (1980): The reliability of shoreline change measurements from aerial photographs, Shore Beach, 48 (10), 22-29.

DubBini, M. and A. ZANuTTA (2005): Terrestrial laser scanning to landslide movements detection, in Proceeding to Workshop Italy-Canada on «3D Digital Imaging and Modeling, Applications of Heritage, Industry, Medicine and Land», 17-18 May 2005, Padova, Italy.

KÄÄB, A. (2000): Photogrammetry for early recognition of high mountain hazards: new techniques and applications, Phys. Chem. Earth., 25 (9), 765-770.

KÄÄB, A. and M. FunK (1999): Modelling mass balance using photogrammetric and geophysical data: a pilot study at Griesgletscher, Swiss Alps. Instruments and Methods, J. Glaciol., 45 (151), 575-583.

Kraus, K. (1997): Photogrammetry, Advanced Methods and Applications (Dümmler-Bonn), vol. 2, pp. 466.

LANE, S.N., K.S. RiChaRdS and J.H. ChandLER (1998): Landform Monitoring, Modelling and Analysis (John Wiley \& Sons), pp. 454.

Mora, P., P. Baldi, G. Casula, M. Fabris, M. Ghirotti, E. MaZZINI and A. Pesci (2003): Global Positioning Systems and digital photogrammetry for the monitoring of mass movements: application to the Cà di Malta landslide (Northern Apennines, Italy), Eng. Geol., 68, 103-121.

OvERTON, M.F. and J.S. FisHER (1996): Application of 3D computer modeling using digital photogrammetry to measure shoreline change, in Proceedings of the 25th International Conference on Coastal Engineering, ASCE, 3, 3750-3761.

Pesci, A., P. Baldi, A. Bedin, G. Casula, N. Cenni, M. FABris, F. Loddo, P. Mora and M. BACChetTi (2004): Digital elevation models for landslide evolution monitoring: application on two areas located in the Reno River Valley (Italy), Ann. Geophys., 47 (4), 1339-1353.

Simoni, A., M. Berti, M. Generali, C. Elmi and M. Ghiotti (2004): Preliminary result from pore pressure monitoring on an unstable clay slope, Eng. Geol., 73, 117-128.

VAN Westen, C.J. and F.L. Getahun (2003): Analyzing the evolution of the Tessina landslide using aerial photographs and digital elevation models, Geomorphology, 54, 77-89.

(received January 22, 2006; accepted July 17, 2006) 